\title{
The state of the art in evaluating the performance of department chairs and division heads.
}

\author{
David G. Dunning \\ University of Nebraska Medical Center, ddunning@unmc.edu \\ Timothy M. Durham \\ University of Nebraska Medical Center \\ Mert N. Aksu \\ University of Nebraska Medical Center \\ Brian M. Lange \\ University of Nebraska Medical Center, blange@unmc.edu
}

Tell us how you used this information in this short survey.

Follow this and additional works at: https://digitalcommons.unmc.edu/cod_articles

Part of the Dentistry Commons

\section{Recommended Citation}

Dunning, David G.; Durham, Timothy M.; Aksu, Mert N.; and Lange, Brian M., "The state of the art in evaluating the performance of department chairs and division heads." (2007). Journal Articles: College of Dentistry. 2.

https://digitalcommons.unmc.edu/cod_articles/2

This Article is brought to you for free and open access by the College of Dentistry at DigitalCommons@UNMC. It has been accepted for inclusion in Journal Articles: College of Dentistry by an authorized administrator of DigitalCommons@UNMC.For more information, please contact digitalcommons@unmc.edu. 


\title{
The State of the Art in Evaluating the Performance of Department Chairs and Division Heads
}

\author{
David G. Dunning, Ph.D.; Timothy M. Durham, D.D.S.; \\ Mert N. Aksu, D.D.S., J.D., M.H.S.A.; Brian M. Lange, Ph.D.
}

Abstract: This study explores the little understood process of evaluating the performance of department chairs/division heads in dental schools. Specifically, this research aimed to elucidate the methods, processes, and outcomes related to the job performance of department chairs/division heads. Forty-three deans and 306 chairs completed surveys with both close-ended and open-ended questions. In addition, ten deans and ten chairs were interviewed. Results indicate that 80 to 90 percent of department chairs are formally evaluated, although as many as 50 percent may lack job descriptions. Recommended best practices for performance appraisal—such as having at least yearly appraisals, holding face-to-face meetings, and setting specific, personal performance objectives/benchmarks for chairs - are being used in most schools. Still, there is much room to improve appraisals by incorporating other recommended practices. Overall high levels of satisfaction were reported by both chairs and deans for the process and outcomes of appraisals. Qualitative data showed some convergence of opinions about appraisals with the notable exception of informal feedback. We explore some implications of these results, especially as they relate to improving performance appraisals.

Dr. Dunning is Professor of Practice Management, Department of Oral Biology, College of Dentistry, University of Nebraska Medical Center; Dr. Durham is Professor and Chair, Department of Hospital Dentistry, and Director of the General Practice Residency, College of Dentistry, University of Nebraska Medical Center; Dr. Aksu is Associate Dean, Clinical Administration, and Associate Professor, Department of Patient Management, School of Dentistry, University of Detroit Mercy; and Dr. Lange is Professor of Behavioral Science, Department of Oral Biology, College of Dentistry, University of Nebraska Medical Center. Direct correspondence and requests for reprints to Dr. David Dunning, Department of Oral Biology, College of Dentistry, University of Nebraska Medical Center, 40th and Holdrege Sts., Lincoln, NE 68583-0740; 402-472-1325 phone; 402-472-2551 fax; ddunning@unmc.edu.

This article presents the findings of a research project, "The State of the Art in Evaluating the Performance of Department Chairpersons and Assistant/Associate Deans in ADEA-Affiliated Dental Colleges," funded by the American Dental Education Association Council of Sections Project Pool.

Key words: performance review, performance appraisal, performance evaluation, department chairs, division heads, deans, dental schools, dental colleges

Submitted for publication 10/9/06; accepted 12/15/06

$\mathrm{V}$ oluminous research has been conducted in organizational behavior and management over the past decades. Fritz Roethlisberger, a co-investigator in the legendary Hawthorne Studies, ${ }^{1}$ published an insightful essay in 1945 about the "foreman." ${ }^{2}$ The foreman's position in the organizational structure mirrors in many ways that of department heads in universities. Persons occupying this middle management role have a dual and often conflictive task: 1) uphold the standards, policies, rules, and regulations that have been developed largely by others (administrators); and 2) ensure that workers conform to the organization, obtaining if possible the workers' spontaneous cooperation to a particular and prescribed way of doing business. Amidst the expec- tations of administrators and faculty members, chairs perform their work in dental schools: recruit, hire, mentor, and evaluate faculty and conduct research, teach, and serve in many capacities. Meanwhile, deans must also manage a similar duality of functions in the reporting structure. The resultant stress in supervising department chairs and being supervised by presidents/chancellors likely contributes to the fact that the typical tenure of deans is only about five years. ${ }^{3}$

Within this volatile context, the drama of hierarchy is enacted as department chairpersons are accountable for their job performance to their immediate supervisors, deans in most cases, and perhaps also assistant and associate deans. Yet, 
relatively little research has been conducted about the formal or informal methods utilized to ensure accountability for administrative job performance in academic health science centers generally and in dental colleges particularly.

Previous studies have discovered an interesting landscape regarding performance appraisals in higher education. Romberg ${ }^{4}$ factor-analyzed a fifty-two-item instrument used by faculty to evaluate the behavior of dental school department chairs, yielding four basic dimensions of performance: departmental management (seventeen items such as accessibility, communication effectiveness, etc.); extradepartmental relations (eight items such as objectivity in evaluating faculty and acceptance of responsibility for departmental mistakes); interpersonal relations (ten items such as being trusted by faculty and making sound decisions); and planning skills (five items such as keeping goals in the forefront and establishing priorities). Other publications have focused on department head and administrator views of faculty appraisals and faculty member perceptions of the appraisals done most frequently by department chairs. ${ }^{5-8}$ Two studies in medical colleges examined, respectively, the use of a faculty member and a department "report card" to monitor performance and implementation of a mission-based reporting system (comparing individual results with merit increases) for deans and department chairs. ${ }^{9-10}$ Another author stressed the need to link 50 percent of available resources to educational excellence in medical schools. ${ }^{11}$

In 1980, Hammons and Thomas noted that "no group is more neglected with regard to evaluation" than the department/division chair. ${ }^{12}$ They constructed an extensive survey on performance appraisals and received responses from 455 chairpersons from community colleges whose administrators agreed to participate. Hammons and Thomas introduced their results section by stating, "The results confirmed our suspicions that there is much to be done in developing appropriate appraisal systems for department/division chairpersons" (p. 42). Among their main findings were the following: only 66 percent of community colleges formally evaluated their department chairpersons; just 9 percent of the chairs reported being evaluated with "objective" standards; both objective and subjective standards were used in 67 percent of evaluations; and only subjective standards were used in 34 percent of appraisals. Finally, "less than half of the chairs appeared to have criteria which they felt were desirable" (p. 45). Hammons and Thomas concluded that while the sources "on performance appraisal in business and industry are voluminous, there is a virtual famine of published articles on this topic in higher education" (p. 48).

Ameliorating this "famine" somewhat is an important three-volume set written by Biebuyck and Mallon and published by the American Association of Medical Colleges. ${ }^{13-15}$ Building upon relevant literature, surveys, institutional documents, interviews, and experience, these three modules detail methods for recruiting, hiring, rewarding, compensating, transitioning leadership for, and evaluating the performance of department chairs in medical colleges.

The third module, ${ }^{15}$ Performance, Evaluation, Rewards, Renewal, relates most directly to the appraisal of department chairs. Biebuyck and Mallon stress that no one system will be a good fit for all institutions; evaluation systems are more likely to be effective when those who are evaluated participate in the system; and truly objective evaluation systems do not exist. Biebuyck and Mallon describe internal and external departmental evaluation procedures - that is, techniques for appraising the performance of departments per se. They also discuss examples of department chair evaluation in specific categories such as administrative leadership skills and professional and staff development and management. In evaluating department chairs, Biebuyck and Mallon recommend the use of multifaceted self-evaluation, attention to the climate for women and minorities, 360-degree feedback (obtaining feedback from all major constituents with which the chair works: faculty, staff, residents, students, other administrators), the need for confidentiality, and the identification of a trend to tie the evaluation of chairs to resource allocation and to strategic institutional initiatives. Module 3 includes as appendices a series of helpful institutional documents: a very detailed job description for assessing chair performance, departmental chair self-evaluation forms from two institutions, and documents elucidating policies and processes related to the evaluation of chairs/division heads.

Some related but more limited literature focuses on the evaluation of deans and assistant/associate deans. In 1975, Fenker ${ }^{16}$ described the development and implementation of several evaluation instruments at one university. The administrative instrument outlined by Fenker included four sections and thirtythree items rated on Likert scales: communication, goal completion, delegation, and personal skills. Romberg et al. ${ }^{17}$ described a system used to evaluate dental school administrators. The evaluation forms 
contained similar categories (problem solving, communication skills, planning skills, etc.) rated from outstanding to inadequate, with a special section for each assistant/associate dean based on individual job functions. Romberg et al. indicated that assistant/associate deans would be evaluated biannually by faculty and students and, ultimately, by the dean in a summative evaluation.

Several articles have addressed the role of deans in the evaluation of faculty. ${ }^{8,18-20}$ Dittmar et al. reported one nursing college's development and utilization of a faculty-based evaluation instrument for appraising the performance of a dean. ${ }^{21}$ Finnerman reported in 1983 that one-half of the deans of nursing colleges did not have access to their performance evaluations. ${ }^{22}$ Biebuyck and Mallon ${ }^{14}$ include an appendix outlining one university's routine review process of chairs, directors, and associate deans, including self-study and a review committee. Biebuyck and Mallon also identify several "downsides" of formal/planned reviews of administrators (specifically, university presidents), including the voicing of too many complaints all at once and the negative impact on important decision making due to the timing of the review rather than the merits of issues. Accordingly, Biebuyck and Mallon recommended the use of more informal review opportunities for administrators.

The extant literature thus indicates a need for more research regarding the evaluation of department chairpersons, particularly in dental colleges. To address this knowledge gap, the goal of this research was to elucidate the state of the art in the methods, processes, and outcomes related to evaluating the job performance of department chairs in dental colleges affiliated with the American Dental Education Association (ADEA).

\section{Methods}

Approval for the project was secured through the first author's institutional review board (IRB \#038-04-EX). Based on the above literature review, draft surveys were constructed for deans and department chairs and were mailed to five deans and ten department chairs for pilot-testing. Four deans and nine department chairs returned draft surveys and provided helpful recommendations for improvement. The final surveys included twenty-two questions for deans and twenty-five questions for chairs, the additional questions pertaining to academic rank and tenure. Questions covered these areas: type of dental school (public vs. nonpublic), length of service, job descriptions, features utilized in performance evaluations, frequency of and length of time since the last performance appraisal, satisfaction with the process, outcomes of evaluations using a five-point scale $(1=$ very dissatisfied to $5=$ very satisfied $)$, rankings of the purposes for evaluations, ratings of the value of appraisals ( $1=$ no value to $5=$ very valuable), open-ended comments regarding appraisals, receipt of informal feedback and its frequency, satisfaction regarding informal feedback (based on the same five-point scale), and an open-ended question for summarizing a particularly successful/unsuccessful story regarding performance appraisals. A few additional questions were tailored for only deans or only chairs (e.g., whether chairs evaluated deans and would like to do so). The electronic survey included a helpful "logic" component whereby participants were automatically directed to certain questions based on their answers. Respondents were also invited to send copies of performance appraisal forms to the authors of this article.

Final surveys were distributed electronically (www.surveymonkey.com). ADEA staff provided the most updated available list of email addresses for all deans and department chairs in dental schools and other programs (hospital and auxiliary programs). The original list of chairs included 759 individuals. In January 2005, a presurvey email announcement (with a link that allowed recipients to decline participation) was sent to sixty-six deans and 759 department chairs in U.S. and Canadian dental schools. The list of 759 chairs was reduced to 599 by excluding from the sample duplicate email addresses, individuals who had left their positions, and individuals who were not in departments with reporting relationships to dental college deans (largely chairs in medical and community colleges). In addition, two dental schools with nondepartmental organizational structures were identified after exchanging emails with their leaders and were excluded from the study. This left, then, sixty-four deans with departmental organizational structures and 589 chairs. Of this number, one dean and nine chairs from the presurvey email declined to participate and were thus not included in the study.

From February through April 2005, emails with links to the survey (and an additional decline participation link) were sent to sixty-three deans and 580 chairs. Email invitations were delivered four times to deans and five times to chairs. Forty-three deans completed the survey, a response of 67.2 percent, 
including the individual who originally declined participation. Three hundred and six department chairs completed the survey, a response rate of 52 percent.

Quantitative data from the surveys was then exported/imported into SAS for analysis. The following statistics were computed: descriptive (means and percentages), comparisons of means using ANOVA, and comparisons of proportional data using chi square analysis. Responses to the two written survey questions were extracted verbatim from the data set and content-analyzed by two members of the research team to identify qualitative categories or themes. Ten deans and fifty-two chairs provided comments related to the frequency, process, outcome, or purpose of performance appraisals. Eighteen deans and 106 chairs provided brief accounts of particularly successful/unsuccessful experiences in the performance evaluation process.

To augment the survey data, two research team members conducted follow-up telephone interviews ranging from ten to twenty-five minutes with a sample of ten deans and ten department chairs stratified to mirror the percentages of survey participation. The eight interview questions covered these topics: key elements of and obstacles to making formal appraisals effective or valuable, an example of an effective or ineffective appraisal, advice for those involved in the performance evaluation process, key elements of and obstacles to making informal feedback effective or valuable, and advice for those who provide informal feedback. These recorded interviews were then also content-analyzed by two research team members.

\section{Results}

\section{Quantitative Survey Findings}

Table 1 reports the overall results of quantitative data for deans and chairs. As could be expected, most respondents were from public schools (69 percent of deans; 66 percent of chairs). Fifty-eight percent of deans and 60.3 percent of chairs had four years or more experience in their positions. While nearly 70 percent of deans reported that department chairs in their dental school had job descriptions, significantly fewer chairs ( 50 percent) reported having job descriptions as chairpersons. The vast majority of both deans and chairs reported that formal chair evaluations were conducted with a frequency of once a year and that it had been twelve months or less since the last appraisal.
Several features of the appraisal process for academic administrators have been commonly recommended in the literature. A list of eight frequently recommended features of the evaluation process appears in Table 1. Respondents indicated a wide range of utilization of these features: from a low of 21.3 percent of chairs reporting that resources are allocated based on department achievement of performance objectives to a high of 97.4 percent of deans reporting the use of a face-to-face meeting for appraisals. Chi square analysis showed significant differences in five of the eight performance review features. Marked differences between deans and chairs of 18.4 percent and 16.5 percent, respectively, were noted regarding the setting of department/division objectives tied to strategic plans/goals and the setting of personal performance objectives.

As might be expected, the highest ranked purpose for evaluations was the assessment of chair/head job performance-ranked exactly the same by deans and chairs at 1.97 (with 1 being the highest rank). Dean and chair average rankings differed significantly for two purposes: deans ranked appraisals as serving the personal development of chairs more highly (deans $=2.41$; chairs $=3.15)$; and chairs ranked appraisals as complying with university policy/procedure more highly (deans $=4.30$; chairs=3.44). Both deans and chairs rated satisfaction with the appraisal process and with evaluation outcomes at fairly high levels (3.81 to 3.97 on a scale of 1 to 5 with 5 being very satisfied). Deans viewed appraisals as being more valuable than chairs to the personal development of chairs (3.92 vs. 3.32, ANOVA $p=.04$ ). Whereas all deans reported giving informal feedback to chairs, only 74 percent of chairs reported receiving such feedback, a significant difference (chi square $\mathrm{p}=.0002$ ). A majority of 56 percent of deans and 58 percent of chairs indicated that informal feedback is typically given only when necessary - namely, when a concern or something praiseworthy arises. Satisfaction with informal feedback was rated at 3.95 by deans and at 3.82 by chairs. Almost 73 percent of chair respondents were tenured full or associate professors, and the remaining 27 percent reported that they were not tenured. Forty-seven percent of the individuals in the latter category reported they held clinical, non-tenure track positions. Most chairpersons (54.9 percent) do not have the opportunity to provide formal feedback to their deans/supervising administrators, although 68.8 percent would like this opportunity. 


\begin{tabular}{|c|c|c|}
\hline Survey Item & $\begin{array}{l}\text { Deans } \\
(\mathrm{n}=43)\end{array}$ & $\begin{array}{l}\text { Department Chairs/ } \\
\text { Division Heads }(n=307)\end{array}$ \\
\hline \multicolumn{3}{|l|}{ Type of School/College } \\
\hline Private & $25.6 \%$ & $23.9 \%$ \\
\hline Private state-related (some public funding) & $4.7 \%$ & $8.8 \%$ \\
\hline Public & $69.8 \%$ & $66 \%$ \\
\hline \multicolumn{3}{|l|}{ Length of Service } \\
\hline 3 years or $<$ & $42 \%$ & $39.7 \%$ \\
\hline 4 years or $>$ & $58 \%$ & $60.3 \%$ \\
\hline \multicolumn{3}{|l|}{ bb Descriptions for Chairs/Heads ${ }^{*}$} \\
\hline Yes & $69.8 \%$ & $50 \%$ \\
\hline No & $30.2 \%$ & $39.5 \%$ \\
\hline Unsure & $0 \%$ & $10.5 \%$ \\
\hline \multicolumn{3}{|l|}{ Formally Evaluated } \\
\hline Yes & $90.7 \%$ & $79.7 \%$ \\
\hline No & $9.3 \%$ & $20.3 \%$ \\
\hline \multicolumn{3}{|l|}{ Features of Evaluation Process } \\
\hline Using structured/close-ended questions & $59 \%$ & $58.7 \%$ \\
\hline Using unstructured/open-ended questions ${ }^{* *}$ & $51.3 \%$ & $40.4 \%$ \\
\hline Setting of speci c, personal performance objectives/benchmarks ${ }^{\star \star}$ & $76.9 \%$ & $60.4 \%$ \\
\hline $\begin{array}{l}\text { Setting department/division objectives on basis of college or university } \\
\text { strategic plan/goals }{ }^{* *}\end{array}$ & $66.7 \%$ & $48.3 \%$ \\
\hline $\begin{array}{l}\text { Allocating resources based on department achievement of } \\
\text { performance objectives }\end{array}$ & $28.2 \%$ & $21.3 \%$ \\
\hline Meeting face-to-face to review ${ }^{* \star}$ & $97.4 \%$ & $90.4 \%$ \\
\hline $\begin{array}{l}\text { Assimilating feedback from at least one source in addition to the } \\
\text { dean or his/her designee }\end{array}$ & $48.7 \%$ & $36.5 \%$ \\
\hline Chair/head self-evaluation/appraisal & $53.8 \%$ & $50.9 \%$ \\
\hline \multicolumn{3}{|l|}{ Frequency of Appraisal } \\
\hline$<1$ a year & $2.6 \%$ & $7.8 \%$ \\
\hline 1 a year & $94.9 \%$ & $87.1 \%$ \\
\hline 2 a year & $2.6 \%$ & $4.3 \%$ \\
\hline$>2$ a year & $0 \%$ & $0 \%$ \\
\hline \multicolumn{3}{|l|}{ Time Since Last Evaluation } \\
\hline$<6$ months & $30.8 \%$ & $31.9 \%$ \\
\hline $6-12$ months & $51.3 \%$ & $56.2 \%$ \\
\hline $1-2$ years & $15.4 \%$ & $7.5 \%$ \\
\hline$>2$ years & $2.6 \%$ & $4.4 \%$ \\
\hline \multicolumn{3}{|l|}{ Ranked Purposes of Appraisals (1-5 with 1 the most important purpose) } \\
\hline Personal development of chair/head $* * *$ & 2.41 & 3.15 \\
\hline Usti $\sqsubset$ cation for salary adjustment & 3.34 & 3.41 \\
\hline Assessment of job performance of chair/head in that role & 1.97 & 1.97 \\
\hline Assessment of department/division performance in speci $\ulcorner$ c areas & 2.51 & 2.39 \\
\hline Compliance with university policy/procedure ${ }^{\star \star \star}$ & 4.30 & 3.44 \\
\hline Other purpose not listed above & 3.14 & 4.11 \\
\hline Overall Satisfaction with Process (1-5 scale with 5 being very satis ed) & 3.97 & 3.81 \\
\hline Overall Satisfaction with Outcomes (1-5 scale with 5 being very satis $\ulcorner$ ed) & 3.84 & 3.87 \\
\hline \multirow{2}{*}{$\begin{array}{l}\text { Value of Appraisals to Chair/Head Personal Development† } \\
\text { (1-5 scale with } 5 \text { being very valuable) }\end{array}$} & 3.92 & 3.32 \\
\hline & & (Continued) \\
\hline
\end{tabular}




\begin{tabular}{|c|c|c|}
\hline Survey Item & $\begin{array}{l}\text { Deans } \\
(n=43)\end{array}$ & $\begin{array}{l}\text { Department Chairs/ } \\
\text { Division Heads }(n=307)\end{array}$ \\
\hline \multicolumn{3}{|l|}{ Informal Feedback Provided?*** } \\
\hline Yes & $100 \%$ & $74.2 \%$ \\
\hline No & $0 \%$ & $25.8 \%$ \\
\hline \multicolumn{3}{|l|}{ Frequency of Informal Feedback } \\
\hline Once a week or < & $4.9 \%$ & $7.1 \%$ \\
\hline 2-3 times a month & $2.4 \%$ & $5.7 \%$ \\
\hline Once a month & $26.8 \%$ & $15.2 \%$ \\
\hline > Once a month & $9.8 \%$ & $13.7 \%$ \\
\hline Really only when necessary (a concern or something praiseworthy) & $56.1 \%$ & $58.3 \%$ \\
\hline $\begin{array}{l}\text { Satisfaction with Informal Performance Feedback } \\
\text { (1-5 scale with } 5 \text { being very satis ed) }\end{array}$ & 3.95 & 3.82 \\
\hline \multicolumn{3}{|l|}{ Academic Rank } \\
\hline Professor & & $63.5 \%$ \\
\hline Associate Professor & & $28.3 \%$ \\
\hline Assistant Professor & & $6.2 \%$ \\
\hline Other & & $2.0 \%$ \\
\hline \multicolumn{3}{|l|}{ Tenured } \\
\hline Yes & & $72.8 \%$ \\
\hline No & & $27.2 \%$ \\
\hline \multicolumn{3}{|l|}{ If not tenured, on clinical track? } \\
\hline Yes & & $47.3 \%$ \\
\hline No & & $52.7 \%$ \\
\hline \multicolumn{3}{|l|}{$\begin{array}{l}\text { Opportunity to provide formal performance feedback to your } \\
\text { dean/supervising administrator? }\end{array}$} \\
\hline Yes & & $45.1 \%$ \\
\hline No & & $54.9 \%$ \\
\hline \multicolumn{3}{|l|}{$\begin{array}{l}\text { Would you like the opportunity to formally evaluate your } \\
\text { dean/supervising administrator? }\end{array}$} \\
\hline Yes & & $68.8 \%$ \\
\hline No & & $10.6 \%$ \\
\hline Unsure & & $20.6 \%$ \\
\hline $\begin{array}{l}{ }^{*} \text { Chi square } p=.017 \\
{ }^{* *} \text { Chi square } p<.034 \\
{ }^{* *} \text { Chi square } p=.0002 \\
\dagger \text { ANOVA } p<.04\end{array}$ & & \\
\hline
\end{tabular}

In addition to Table 1, comparisons were computed using these independent variables: type of college (public vs. private/private with some public funding); length of service with two groups established based on clusters of respondents (three years or less and four years or more); and tenured vs. nontenured chairs. The following significant differences were noted in comparing public and private schools: public school deans reported incorporating an unstructured form (with open-ended questions) more often than did their private school peers (chi square $\mathrm{p}=.04)$; private school deans reported incorporating evaluation of department goals on the basis of the college/university strategic plan more frequently than their public school peers (chi square $\mathrm{p}=.03$ ); chairs in private colleges ranked personal development more highly than chairs in public schools (2.7 vs. 3.4 , ANOVA $p=.0002$ ); chairs in public colleges ranked compliance with university policy/procedure more highly as a purpose than chairs in private schools ( 3.3 vs. 3.8 , ANOVA $p=.007$ ); and chairs in private colleges rated the value of appraisals to personal de- 
velopment more highly than chairs in public schools (3.5 vs. 3.2 , ANOVA $p=.03$ ).

Several significant differences in the two length of service groups (three years or less experience compared to four years or more) were identified: deans with less experience ranked justification of salary increase more highly as a purpose than deans with more service ( 2.8 vs. 3.8 , ANOVA $p=.04$ ); chairs with less service ranked personal development significantly higher as a purpose than their peers with more experience ( 3.0 vs. 3.4 , ANOVA $p=.05$ ); chairs with less service rated the outcomes of evaluation higher than their peers with more experience ( $4.0 \mathrm{vs}$. 3.7, ANOVA $\mathrm{p}=.03$ ); and chairs with less experience rated the value of appraisals to personal development more highly than their more experienced peers (3.4 vs. 3.1, ANOVA $p=.01$ ). No statistically significant differences emerged based on tenured compared to nontenured chairs.

\section{Qualitative Survey Findings}

Respondents had the opportunity to comment on the frequency, process, outcome, or purpose of appraisals as well as provide accounts of successful or unsuccessful evaluation processes. As to frequency, process, and outcomes, comments often expressed interrelated issues, making it difficult to categorize the data. Consequently, responses were evaluated solely for common themes. Responses regarding individual experiences with the evaluation process for both the chairs and deans typically fell into two major categories of improving or hindering appraisals. The distribution for chairs/division heads revealed thirty-seven comments related to improvements and thirty-four comments about impediments; for deans, nine responses related to improvements and one to hindrances. In addition, deans frequently described how negative issues of performance could be addressed in the evaluation process, leading ultimately to a more positive outcome for the college and improved performance of the chair.

Tables 2 and 3 summarize themes associated with the two open-ended survey questions. Comparison of responses between the chairs and the deans identified the following points of congruence that appear to be key concepts for the successful evaluation.

Frequency/Timing

1. The evaluation should be held on an annual basis, utilizing intermittent meetings of a formal/informal nature throughout the year.
2. The process should be scheduled with enough foresight and planning to allow chairs adequate time for proper development of documents as well as their review by the dean.

3. The annual review process may be enriched by conducting a more in-depth periodic evaluation every three to five years. Similar to tenure and post-tenure review processes, a more thorough periodic appraisal could utilize feedback from additional sources such as a college or institutional committee and/or outside consultants/ reviewers.

Process

1. The process should use a formal standardized tool/instrument that is thorough yet not too complex or time-consuming to complete. It should utilize objective benchmarks that are flexible enough to allow for individual application to the department with respect to teaching, research, and service accomplishments as well as the achievement of established goals/strategic plan priorities.

2. The process should include self-assessment and allow chairs to describe past or future growth opportunities for their own professional development and for their department as a whole.

3. The process requires face-to-face dialogue where meaningful feedback is given for the chair, faculty, and department. The process should be fair, honest, and concise and include acknowledgment of the positive contributions made by the department to the overall mission of the dental school.

4. The process should avoid presentation of "surprise" faculty issues and display respect for lines of authority through the department and within the college.

Outcomes

1. The value of this process is that it enriches communication and engenders a collegial attitude, productive dialogue, and clarification of expectations.

2. Performance reviews align department, college, and institution in the pursuit, application, or extension of resources (dollars, personnel, training, mentoring) in the support (physical, emotional, and economic) of the department as it works toward college and institutional goals.

3. Appraisals should also result in employing the chair's experience, leadership, and expertise in the functions and operations of the college.

Survey respondents were also asked to provide written explanations about why formal appraisals were not done. Three deans and fifty-six chairs 
commented on this topic. The main reasons cited for not providing formal evaluations of chairs were the following: 1) unknown - the reasons for lack of performance evaluations were not clear to respondents; 2) evaluations focused on chairs as faculty members rather than as chairs per se; 3 ) chair appraisals have not been developed yet, are not part of the culture or policy, or have not been implemented; 4) informal feedback methods are utilized in place of formal evaluations; 5) systems/tools are in the

Table 2. Survey themes of chairs (not listed in any particular order)

Items That Improve or Make the Process Successful

Standardized process that uses objective benchmarks.

Individualized to the department with respect to its role in teaching, research, and service and meeting the strategic plan.

Fair and concise.

Acknowledges the contributions of the chair in successful resolution of dif $\square$ cult issues.

Encourages chair growth by providing direction with respect to leadership and performance.

Seeks alignment of department, college, and institutional goals.

Includes self-assessment.

Completed on an annual basis with intermittent formal/ informal meetings.

Incorporates a more extensive institutional or outside consultant review of the department every three to $\square$ ve years.
Items That Hinder or Impede the Process

Successful performance does not translate into meaningful remuneration.

Process focuses on department outcomes and faculty development and fails to adequately invest in the development of the chair or division head.

The evaluation process is perceived as being mainly a mandatory process necessary to meet institutional or accreditation standards.

Being penalized for poor followership of faculty.

Disconnect between department and college vision.

Failing to appreciate experience of chairs.

Missing opportunities for consensus-building.

Failing to respect the line of authority through the chair position.

Surprise issues are brought up during evaluation process.

Cumbersome paperwork related to the review process.

Table 3. Survey themes of deans (not listed in any particular order)

Items That Improve or Make the Process Successful

Items That Hinder or Impede the Process

Used to mentor young chairs and direct faculty development.

Potential for strong emotional responses.

Improved interactions between departments.

Clari cation of responsibilities.

Should include shorter and intermittent meetings for follow-up.

Allows for the direction of resources to the department for skill training.

Is appropriately timed and is held annually, in a face-to-face manner.

Includes a self-assessment process for the chair.

Aligns chair/department with college/institution mission, vision.

Compares chair accomplishments to strategic plan.

Utilizes a form and/or the development of a portfolio or dossier of accomplishments.

Is honest.

Utilized in the removal of nonproductive chairs, reduction of areas of responsibility or redistribution of workloads within the department, and redirection of departmental active ties to improve performance. 
process of being developed; and 6) workloads/other priorities.

\section{Interview Themes}

Deans and chairs were asked questions that explored their experiences in the use of formal and informal evaluation techniques. Tables 4 and 5 present a summary of responses. The chairs and deans shared common views on the use of formal evaluations. However, they had very diverse views on the use of informal feedback as an evaluation tool.

Deans and chairs agreed that effective formal evaluations should be related to outcomes (such as annual departmental reports/strategic plans) and should be based on goals that are agreed on in advance. Additionally, deans felt chairs should be evaluated on how well they managed their departments. Chairs felt the evaluation process should include feedback from peers and students.

Deans agreed on key obstacles that prevented formal performance reviews from being effective, including interpersonal issues with faculty, finding time to dedicate to the task, and lack of resources to link performance to reward.

Deans felt not having goals and timelines as a reference before the evaluation made for an ineffective performance evaluation. Deans also felt that poor conduct such as defensiveness or anger by the person during the evaluation interview/meeting led to an ineffective formal evaluation. The chairs indicated as a group that they were not aware of any problems in the formal evaluation process.

The advice that deans and chairs gave to anyone involved in giving performance reviews was to have a comprehensive review process based on performance. Both groups recommended the consistent use of an evaluation form and administration of the review during the same time each year. Chairs also thought that being truthful was a key element in a performance review. Deans and chairs both recommended the use of a formal evaluation process geared toward continual improvement.

Deans and chairs had very diverse views on the use of informal feedback. Deans felt informal feedback should be based on a trusting relationship, done in private, frequent, and encouraging. Chairs indicated that it is a challenge to utilize informal feedback effectively, but that it may be particularly helpful in breaking the unproductive work habits of individuals.

Deans felt that the obstacles to giving informal feedback included feedback not being accepted by the chair if it did not match their self-image or was inconsistent with what they heard from other people. Chairs identified that in some cases different work hours made it difficult to give feedback. They were also concerned that informal feedback did not allow for documentation.

Chairs advised that informal feedback should be professional, tactful, specific, and positive. Deans advised that informal feedback should involve listening more than talking.

\section{Discussion}

It is important in interpreting these results to note that it is common for differences to exist in comparing people's opinions at different organizational levels. In 1968, Tompkins coined the term "semantic information distance" ${ }^{23}$ to describe the tendency, in simple terms, that "what you see depends upon where you sit." Some of the results of this research mirror this tendency. Additionally, it is likely that participation levels in the study varied from college to college-for example, the chairs but not the dean from a given school could have completed the survey. This variability could also contribute to differences in the responses of chairs and deans.

The vast majority of dental schools provide formal evaluations of department chairs, although 20 percent of chairs indicated that no formal appraisals are given. Nearly 70 percent of deans responded that chairs had job descriptions compared to 50 percent of chairs. Such a discrepancy does lead to a question about the very foundation of human resource management in any organization: job analysis and the resultant job descriptions. If 30 to 50 percent of department chairs are functioning without this foundational documentation, processes based in part on understandings reflective in such records may result in conflict and confusion.

The only recommended feature of appraisals being implemented by 90 percent or more of schools is the use of face-to-face meetings. Additionally, appraisals are being done by approximately 95 percent of dental schools as recommended at least once a year. However, there is much improvement needed in augmenting appraisals through implementing the following features more consistently (currently reported utilization rates of deans and chairs are indicated in parentheses): using structured/closedended questions (59 percent and 59 percent); using unstructured/open-ended questions (51 percent and 
Table 4. Interview themes of chairs

Q1 Chairs identi ed the key elements in performance evaluations:

A. Having a speci c process with criteria that you follow.

B. Have a set of goals that have been agreed on in advance, so agreement

C. Evaluation process should include feedback from peers and students.

Q2 The key obstacles in performance evaluations were identi $\sqsubset$ ed as follows:

A. Some people do not listen or refuse to accept what is said.

B. Finding time to do the evaluations one-on-one.

C. Lack of resources to reward faculty.

Q3 Chairs were not aware of any problems in the evaluation process

Q4 Advice to people involved in performance evaluations included:

A. Implement a comprehensive review process and help individuals get

B. $\quad$ Beady for their review.
B.

Q5 Key elements that make informal feedback effective:

A. Use it to break bad habits and to set stage for what individuals need to do. B. Informal feedback can be dif $\square$ cult to use.

Q6

Barriers that kept informal feedback from being effective were:

A. People not being available/odd hours.

B. The process does not allow for documentation.

Q7

Advice to those who would provide informal feedback:

A. Use tact.

C. Be professional and positive.

40 percent); setting of objectives for personal and department performance ( 77 percent and 60 percent); setting department/division objectives based on the college/university strategic plan/goals (67 percent and 48 percent); allocating resources (albeit typically scarce!) based on department achievement ( 28 percent and 21 percent); assimilating feedback from more than one source (49 percent and 37 percent); and incorporating self-evaluation/appraisal (54 percent and 51 percent).

The overall relatively low utilization levels of recommended features of performance appraisals are somewhat surprising given that surveys often have a certain social desirability influence..$^{24}$ This social desirability influence could have resulted in respondents answering in a way to make actions look more positive in the area of utilization of the appraisal features listed on the survey. This may suggest that the utilization of these best practices is lower than reported in this article.
Even though there is much room for enhancement, levels of satisfaction with both process and outcomes tend to be fairly high (nearly 4 on a 5-point scale) for both deans and chairs. Some disconnect, however, typifies the value of appraisals for chairs' personal development with chairs viewing the process as significantly less valuable.

An opportunity for enhancing the performance evaluation of deans may exist given that 55 percent of chairs do not have the opportunity to give formal feedback and, of these, 69 percent would like this opportunity. Such a process could be structured to provide constructive feedback incorporating some of the recommended features of appraisals such as both open-ended and closed-ended questions. Such an "upward" evaluation process is often recommended and warrants further study focused on academic administrators.

We were surprised at the limited number of significant differences that emerged based on type of

Journal of Dental Education - Volume 71, Number 4 
Table 5. Interview themes of deans

Q1

The deans view an effective evaluation of a department chair to be:

A. Related to the outcomes of their annual report/strategic plan of the college.

B. How well they mentored faculty and managed their department.

Q2

The deans felt that the following were key obstacles that prevented a formal performance review from being effective:

$$
\begin{array}{ll}
\text { A. Interpersonal issues with faculty. } \\
\text { B. Time dedicated to the task. } \\
\text { C. } \quad \text { No clear link to performance and reward. } \\
\text { D. } \quad \text { Chairs viewing the process as negative. }
\end{array}
$$

Deans stated that an ineffective formal performance review included:

A. Not having goals and timelines as references before the evaluation.

B. Poor conduct of the chair at the time of the evaluation.

The advice deans gave to those involved in performance reviews included:

A. Have a developed system of evaluation based on performance.

B. Be consistent with forms used and time of year review is done.

Key elements in giving informal feedback are summarized as:

$\begin{array}{ll}\text { A. } & \text { It should be frequent and encouraging. } \\ \text { B. } & \text { Be based on a trusting relationship. }\end{array}$

C. Be done in private.

Issues that presented as obstacles to giving informal feedback included:

A. Not be accepted by the person if it does not match their self-image.

B. If the feedback they hear from you is not consistent with what others say.

college (private vs. nonprivate), length of service, and tenure of chairs. In summarizing the several differences in private vs. nonprivate schools, there appears to be a tendency toward slightly more accountability among private schools (deans reporting setting more goals based on strategic initiatives; chairs ranking and rating personal development more highly). Length of service also resulted in some differences: less experienced chairs ranked and rated personal development more highly, and less experienced deans ranked justification of salary increase more highly.

Considerable overlap in perspective emerged based on the deans' and chairs' recommendations for effective components of performance appraisal in the qualitative survey and interview data: standardized process/forms, clearly stated expectations, goals/ objectives, flexibility in applying to individuals and departments, the need for fairness, professionalism, honesty, self-assessment, and alignment with department/college/institutional goals. These consistencies may be attributable to the fact that interviewees volunteered to participate and may have been more inclined to be interested in pursuing excellence in appraisals.

The qualitative data did, however, reveal that deans and chairs hold disparate opinions regarding the role and use of informal feedback. This technique also received fairly high ratings of satisfaction, yet deans report significantly more use of informal feedback than chairs acknowledge receiving (100 percent vs. 74 percent). This may indicate a difference in communication perspectives: intention of deans compared to the interpretation of messages by chairs. There may be a need for more direct communication of intention and purpose with respect to informal performance feedback messages. Ideally, informal feedback should pave the way to formal reviews so that the formal review essentially summarizes the informal feedback. Giving feedback really only when necessary may not achieve this 
worthwhile ideal. Interestingly, chairs tended to see lack of documentation as a barrier to using informal feedback. This trend may indicate a need to enhance the training of chairs in documenting informal feedback. Namely, chairs can record both positive and negative instances of performance by writing brief accounts and then include these in yearly evaluation dossiers. These documented critical incidents can help inform decisions about merit increases or disciplinary interventions.

Results of the study need to be tempered somewhat by the response rate. The 52 percent participation level for chairs and 67 percent for deans are considered, respectively, adequate and good for return rates, ${ }^{24}$ particularly since this sample included nearly the entire population of ADEA-affiliated chairs and deans. Still, higher levels of response rate certainly could have contributed to different results.

\section{Conclusion}

This study represents one of the first comprehensive reviews of performance appraisal processes for department chairs in dental schools. Findings tend to loosely parallel the literature on performance evaluations and their applications in academic settings. While remembering the words of caution from Biebuyck and Mallon that no one system is a good fit for all, the study provides the following summary recommendations for the performance process for department chairs:

1. Performance evaluations should be done on a yearly basis and conducted during a time framework that complements the academic calendar. For example, if performance reviews are tied to the annual budgeting process, then appraisals can be scheduled at the start of the budgetary process.

2. The performance review should utilize a standardized yet department-specific form with both open- and closed-ended questions. The dean and chairs should seek to customize the evaluation form so that it meets institutional requirements but also personalizes the department chair's role in the college. Each department chair evaluation form should assess the contributions of the department without being labor-intensive. Conducting reviews during budget preparation, coupled with the institutionalized/cumbersome nature of some evaluation forms, likely contributes to the perspective that the review is simply done to meet university obligations. Specific con- tent to include in evaluation forms can be found in publications by Romberg ${ }^{4}$ and Biebuyck and Mallon. ${ }^{15}$ A number of helpful survey respondents also forwarded to us copies of evaluation forms currently being utilized in dental colleges. The development of an evaluation tool should be a joint effort of the dean's office and the chairs. Each category can then include departmentspecific criteria with respect to the departmental role within the college and institution. This department specificity is important. For example, using research-based criteria that have not been tailored to a clinical-based department would send an unrealistic and inconsistent message to the chair being evaluated.

3. The formal review process should be supplemented with timely, relatively private informal feedback. Informal feedback can be formalized through the use of a dossier that documents such encounters. Informal feedback can be made more effective when it reinforces the feedback in the formal process. As such, the formal process should avoid major surprises not previously covered through informal feedback.

4. The review process should result in a strategic alignment of resources (monetary, technical, and human) in order for the college and departments to meet their individual and collective missions. Such alignment creates a common language and a shared vision that, in turn, decrease ambiguity and lead to greater consensus and effort toward achieving priorities.

5. The departmental evaluation process seems to focus, perhaps by default, on the department and its faculty. However, the growth and development of the chair should also be an integral purpose in this process. Although deans tended to appreciate the need to develop effective chairs, such efforts appear to be poorly communicated to or appreciated by the chairs. This may be due to a failure to implement many of the previously identified recommendations and/or to frame department chair growth and development within the context of how to improve department performance. Focusing on the individuality of the department chair and emphasizing the professional growth of chairs both need to be priorities in the review process.

6. Deans should consider linking exemplary performance of chairs to rewards of travel, continuing education, and faculty development. Chairs can also be rewarded by having department priorities placed higher on the college or university funding queue.

Journal of Dental Education - Volume 71, Number 4 
7. Incorporating performance feedback from multiple sources (dean, chair self-evaluation, faculty, other administrators, students) should help to minimize bias.

8. The performance review process should clearly model the standards of professionalism, honesty, and fairness.

\section{Acknowledgments}

The authors would like to thank the reviewers of this manuscript for their helpful suggestions. We also thank Mr. Daryl Travnicek of the Department of Statistics, University of Nebraska-Lincoln, for providing data analysis services. Finally, we thank the ADEA Council on Sections Project Pool and the Section on Practice Administration for funding this research.

\section{REFERENCES}

1. Roethlisberger FJ, Dickson WJ. Management and the worker. Cambridge: Harvard University Press, 1939.

2. Roethlisberger FJ. The foreman: master and victim of double talk. Harvard Bus Rev 1945;23(spring):285-94

3. Wolverton M, Gmelch WH, Montez J, Nies CT. The changing nature of the academic deanship. ASHE-ERIC higher education research report 2001;28(1/April).

4. Romberg E. Dimensions of faculty evaluation of chair behaviors. J Dent Educ 1985;49(8):584-8.

5. McDowell EE. Administrators' perceptions of the performance appraisal interview. Minneapolis: University of Minnesota, 1999.

6. Keith CL, Weiss SA, Leo AL. The role of department chairmen in faculty evaluation. J Dent Educ 1978;41(6): 324-8.

7. McDowell EE. Administrators' and faculty members' perceptions of the performance appraisal interview. Paper presented at the $72^{\text {nd }}$ Annual Meeting of the Speech Communication Association, Chicago, IL, November 1986.

8. Jones RF, Froom JD. Faculty and administration views of problems in faculty evaluation. Acad Med 1994;69(6): 476-83.

9. Garson A Jr, Strifert KE, Beck JR, Schulmeier GA, Patrick JW, Buffone GJ, Feigin RD. The metric process: Baylor's development of a "report card" for faculty and departments. Acad Med 1999;74(August):861-70.
10. Howell LP, Hogarth MA, Anders TF. Implementing a mission-based reporting system at an academic health center: a method for mission enhancement. Acad Med 2003;78(6):645-51

11. Reiser SJ. Linking excellence in teaching to departments' budgets. Acad Med 1995;70(4):272-5.

12. Hammons J, Thomas W. Performance appraisal of community college department/division chairpersons. Comm Coll Rev 1980;7(3):41-9.

13. Biebuyck JF, Mallon WT. The successful medical school department chair: a guide to good institutional practice. Module I: search, selection, appointment, transition Washington, DC: Association of American Medical Colleges, 2002.

14. Biebuyck JF, Mallon WT. The successful medical school department chair: a guide to good institutional practice. Module II: characteristics, responsibilities, expectations, skill sets. Washington, DC: Association of American Medical Colleges, 2002.

15. Biebuyck JF, Mallon WT. The successful medical school department chair: a guide to good institutional practice. Module III: performance, evaluation, rewards, renewal. Washington, DC: Association of American Medical Colleges, 2002.

16. Fenker RM. The evaluation of university faculty and administrators. J High Educ 1975;46(6):665-86.

17. Romberg E, Hovland EJ, Singer J, Myslinski NR. The development and implementation of a system to evaluate dental school administrators. J Dent Educ 1982; 46(10):581-5

18. Jones JE, Preusz GC. Evaluating dental faculty performance: perceptions of dental school deans. Psychol Rep 1989;64:647-51.

19. Boozer CH, Lee MM, Rayson JH. Faculty evaluation: a survey of dental school administrators. J Am Coll Dent 1981; 48(2):102-7.

20. DiBiaggio J. The role of the dean in the evaluation process. J Dent Educ 1977;41(6):320-3.

21. Dittmar SS, Stuart CT, Elder RG. Evaluation of the school of nursing dean. J Nurs Educ 1990;29(6):283-5.

22. Finnerman MR. Trends in the evaluation of nursing deans. Nurs Outlook 1983;31(3):72-5.

23. Tompkins P. Organizational communication: a state-of the-art review. In: Richetto $\mathrm{G}$, ed. Conference on organizational communication. Huntsville, AL: MSFC/NASA, 1968:4-26.

24. Babbie E. The practice of social research. $3^{\text {rd }} \mathrm{ed}$. Belmont, CA: Wadsworth, 1983:esp. chapters 6 and 9 